Paul Rees

\section{Safety and feasibility of a strategy of early central venous catheter insertion in a deployed UK military Ebola virus disease treatment unit: response to comments by Bordes et al.}

Accepted: 6 April 2015

Published online: 14 May 2015

(C) Springer-Verlag Berlin Heidelberg and ESICM 2015

Dear Editor,

On behalf of my co-authors, I thank Dr. Bordes et al. for their correspondence regarding our recently published paper [1], in which they highlight the difficulties associated with the management of venous access in severely ill patients with Ebola virus disease-related encephalopathy [2].
It was our practice to institute central venous access early, once gastrointestinal disease was present, and the majority of our caseload arrived early enough in their clinical course that this was possible. However, a number of cases did present with more advanced disease, so we did need to address this specific issue. As outlined, the vast majority of our cases received small aliquots of intravenous benzodiazepine, administered by senior operators experienced in procedural sedation and anaesthesia. Our group encountered no adverse events related to procedural sedation within the "red zone", although all operators had prior experience of providing critical care on austere military operations.

We found that careful, planned sedation was adequate to safely facilitate central venous catheter insertion. On occasions where an alternative sedation agent was necessary to facilitate general supportive care, small aliquots of haloperidol were used. Although encephalopathy and agitation was not viewed as a contraindication to central venous access per se, generally it heralds a dismal prognosis in the care setting we described.

\section{References}

1. Rees PSC, Lamb LE, Nicholson-Roberts TC, Ardley CN, Bailey MS, Hinsley DE, Fletcher TE, Dickson SJ (2015) Safety and feasibility of a strategy of early central venous catheter insertion in a deployed UK military Ebola virus disease treatment unit. Intensive Care Med. doi:10.1007/s00134-015-3736-y

2. Bordes J, Gagnon N, Karkowsky L, Cournac JM, Rousseau C, Billhot M, de Greslan T, Moroge S, Cellarier G (2015) Comments on Rees et al.: safety and feasibility of a strategy of early central venous catheter insertion in a deployed UK military Ebola virus disease treatment unit. Intensive Care Med. doi: 10.1007/s00134-015-3803-4

P. Rees (®)

Academic Department of Military Medicine \& Department of Cardiology, Barts Health NHS Trust, London, UK

e-mail: drpscrees@aol.com 